\title{
Photo-Induced Linkage Isomerism of Transition Metal Nitrosyl and Dinitrogen Complexes Studied by Photocrystallographic Techniques
}

\author{
Dmitry V. Fomitchev, Irina Novozhilova and Philip Coppens* \\ Department of Chemistry, Natural Sciences Complex, State University of New York at Buffalo, Buffalo, NY 14260-3000, USA
}

Received 29 December 1999; revised 7 March 2000; accepted 10 March 2000

\begin{abstract}
New metastable species are formed by low-temperature irradiation of crystals of transition metal nitrosyl complexes. In the work described, photocrystallographic techniques, in which crystals are exposed in situ, are combined with differential scanning calorimetry measurements, IR spectroscopy and theoretical calculations. The new species are identified as isonitrosyl and $\eta^{2}$-NO linkage isomers, which revert to the ground state on subsequent warming. The stability of the linkage isomers increases with increasing $\pi$-withdrawing ability of the ligand trans to NO, indicating the crucial role of electronic factors in determining relative stability of the isomers of different complexes. Isomers with decay temperatures up to $\sim 0^{\circ} \mathrm{C}$ have been prepared. Solid state effects are evident from comparison of the behavior of different salts of the same ion, of sodiumnitroprusside in the neat crystal and in a co-crystal with 18-crown- 6 ether, and from the observation of different photochemical behavior when $\left[\mathrm{Ru}(\mathrm{NO})\left(\mathrm{NH}_{3}\right)_{5}\right]\left(\mathrm{NO}_{3}\right)_{3}$ is absorbed in a sol-gel glass. The two independent molecules in the asymmetric unit of $\left[\mathrm{Ni}(\mathrm{NO})\left(\eta^{5}-\mathrm{Cp}^{*}\right)\right]$ show different orientations of the $\eta^{2}$-NO ligand after irradiation, the difference being related to the shape of the reaction cavities at the two sites. A previously unknown side-on binding mode, similar to that occurring for NO, has been discovered for the dinitrogen ligand in $\left[\mathrm{Os}\left(\mathrm{NH}_{3}\right)_{5}\left(\mathrm{~N}_{2}\right)\right]\left[\mathrm{PF}_{6}\right]_{2}$, indicating the potential of the techniques used in the search for new species and novel binding modes of transition metal atoms. (C) 2000 Elsevier Science Ltd. All rights reserved.
\end{abstract}

\section{Introduction}

The effect of light on crystals of sodium nitroprusside dihydrate $\left(\mathrm{Na}_{2}\left[\mathrm{Fe}(\mathrm{CN})_{5}(\mathrm{NO})\right] \cdot 2 \mathrm{H}_{2} \mathrm{O}\right.$, or $\mathrm{SNP}$, was discovered in $1977 .{ }^{1}$ At that time and long after, the lightinduced species were classified as electronically excited states, even though their unusually long lifetimes at low temperature raised questions about this interpretation, given the diamagnetic nature of the light-induced species. A large body of valuable information on the thermodynamics, kinetics and other properties of SNP and other nitroprusside salts was obtained in subsequent studies (see for example Refs. 2-5).

In the same year as the discovery of the light-induced metastable states of SNP, but apparently quite unrelated, Rest and co-workers observed light-induced changes in $\left[\mathrm{Ni}(\mathrm{NO})\left(\eta^{5}-\mathrm{Cp}\right)\right],{ }^{6}$ and concluded that electron transfer from the metal to the nitrosyl ligand was involved, with possible bending of the $\mathrm{M}-\mathrm{N}-\mathrm{O}$ group. Perhaps because SNP is an $\{\mathrm{MNO}\}^{6}$ complex in terms of the notation introduced by Enemark and Feltham, ${ }^{7}$ while $\mathrm{Ni}(\mathrm{NO}) \mathrm{Cp}$ is

Keywords: photocrystallography; nitrosyl compounds; side-bound dinitrogen; reaction cavity; solid state effects; isonitrosyl complexes; side-bound nitrosyl; DSC; infrared spectroscopy; X-ray analysis.

* Corresponding author. Fax: +1-716-645-6948;

e-mail: coppens@acsu. buffalo.edu
$\{\mathrm{MNO}\},{ }^{10}$ the relation between the two sets of observations appears not to have been noticed for at least a decade.

Our initial interest in the light-induced transition metal nitrosyl species stemmed from their classification as electronically excited states. Given the long lifetimes $\left(\tau>10^{7} \mathrm{~s}\right.$ at liquid nitrogen temperature), the compounds seemed intriguing candidates for excited state diffraction studies. In the synchrotron-based experiments on excited state species, low-temperature diffraction is combined with in situ laser-excitation, and pulsed laser and X-ray sources are used in time resolved experiments of short-lived species. We have proposed the name photocrystallography to describe the field, which combines photochemistry and crystallography in single experiments. The work described here did not require synchrotron radiation, but provided valuable experience in combining the crystallographic and spectroscopic techniques.

\section{Techniques Used}

In situ irradiation of a diffractometer-mounted, cryogenically cooled crystal is the preferred method for studying the geometry of geometry short-lived metastable and excited species. In our first experiments this was accomplished with liquid nitrogen cooling and a classical fourcircle diffractometer equipped with a scintillation detector. 


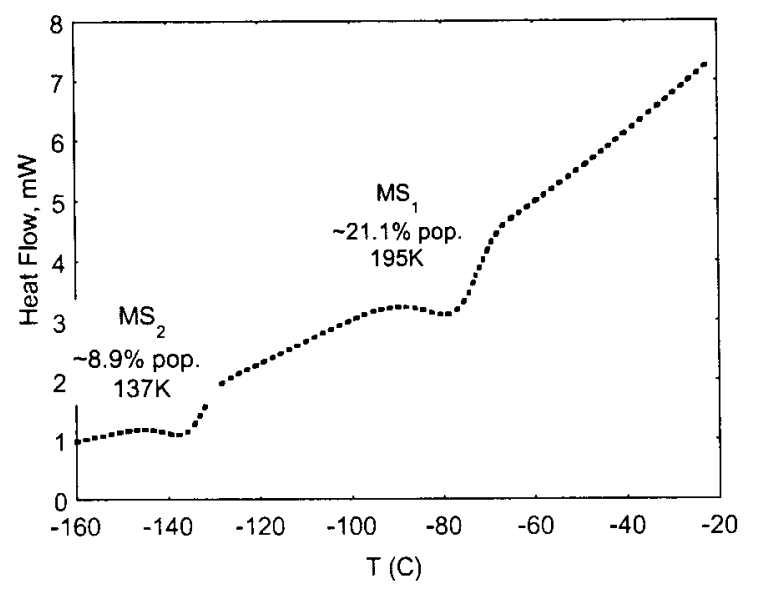

(-) American Chemical Society. Reproduced with kind permission

Figure 1. Differential Scanning Calorimetry (DSC) curve for a laserirradiated crystal of sodium nitroprusside. ${ }^{12}$

The experiment is much facilitated by the use of area detectors such as imaging plates and more recently CCD detectors, while the scope of the studies is extended by the use of helium cryostats or helium gas-flow systems. The use of a cryostat requires light-transparent windows in an X-ray transparent vacuum chamber. ${ }^{8} \mathrm{He}$ gas flow systems give less restricted access to the sample, and thus simplify installation of fluorescence and absorption probes, but tend to be much more expensive to operate. The choice of laser depends, of course, on the absorption spectrum of the system to be studied. In our work we have used $\mathrm{Ar}^{+}$, $\mathrm{He}-\mathrm{Cd}$ and $\mathrm{Nd}-\mathrm{YAG}$ lasers.

To confirm the presence of a photo-induced species prior to conducting the crystallographic experiment, other techniques must be employed. Foremost among these is differential scanning calorimetry (DSC) of a sample previously exposed in situ to light at low temperature. Such a DSC scan for $\mathrm{Na}_{2}\left[\mathrm{Fe}(\mathrm{CN})_{5} \mathrm{NO}\right] \cdot 2 \mathrm{H}_{2} \mathrm{O}$, sodium nitroprusside (SNP), showing the existence of two different light-induced species, labeled MS1 and MS2, is shown in Fig. 1. The quantitative measurement of the heat flow to a sample of

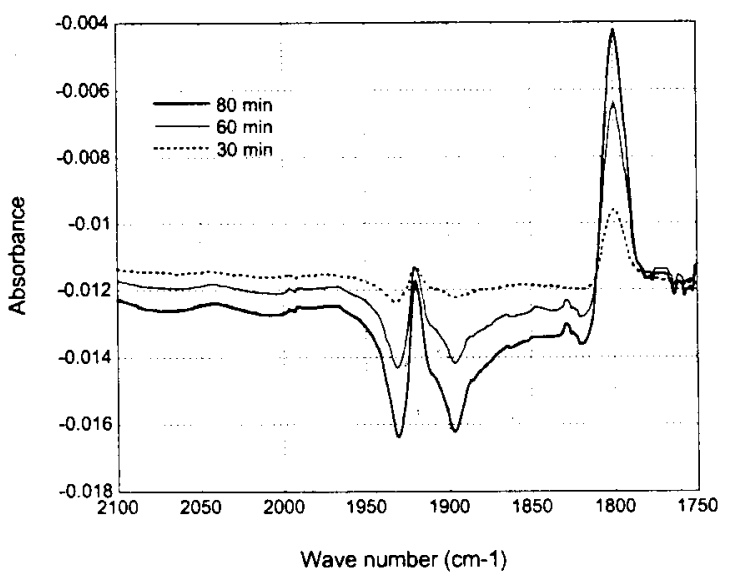

Figure 2. Difference spectrum of $\left[\mathrm{Ru}\left(\mathrm{NH}_{3}\right)_{5}(\mathrm{NO})\right] \mathrm{Cl}_{3}$ after irradiation with 320-350 nm light, as a function of time. Note the weakening of the NO bands in the 1900-1950 region and the appearance of the band, assigned to $\mathrm{ON}$, at $1800 \mathrm{~cm}^{-1}$.

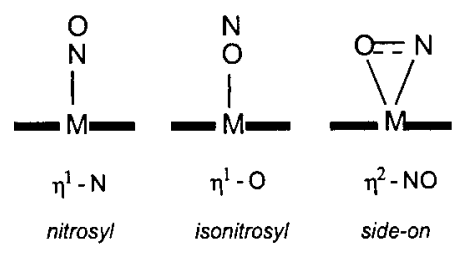

Scheme 1.

known weight at a constant rate of temperature increase, allows an estimate of the conversion percentage, provided the difference in enthalpy of the two states is known at least approximately.

As the conversion is generally incomplete, the photoexcited crystal contains at least two different species. Small changes in cell dimensions, indicative of the change in molecular shape of part of the molecules occur upon photo-illumination. In none of the systems we have studied were superstructure reflections observed, indicating the absence of long range ordering of the light-induced species. One is thus dealing with a disordered system. However, unlike in conventional disordered crystals, precise information is available on the packing and geometry of one of the components since the parent structure is known. It is important to use this information in the subsequent analysis.

The first step in the crystallographic analysis is the calculation of a photodifference map, showing the electron density difference between the irradiated and pristine crystals. The second step is the modeling of the photo-induced species based on the information from the photodifference map, and its introduction in the subsequent least-squares analysis. To obtain the structure of the metastable state, the ground state molecule is treated either as a rigid-body, or as a pseudorigid body, by applying strong restraints to deviations from the ground state structure. The positional parameters of the atoms of the metastable species are refined, together with the population of the metastable state. Temperature factors of atoms remote from the photoactive site may be fixed at their ground state values.

A second method that has been traditionally employed to detect photo-induced changes is infrared spectroscopy. ${ }^{9-11}$ It remains a highly sensitive and fast method for examining samples prior to further analysis. A difference IR spectrum showing the change as a function of exposure time in a spectrum of $\left[\mathrm{Ru}\left(\mathrm{NH}_{3}\right)_{5}(\mathrm{NO})\right] \mathrm{Cl}_{3}$ upon irradiation is shown in Fig. 2. The observed downshift of the NO stretching bands by $100-150 \mathrm{~cm}^{-1}$ is characteristic for the photoactive transition metal nitrosyl complexes. In several cases a second photo-induced band downshifted by about $300 \mathrm{~cm}^{-1}$ or more is observed. The nature of the new species is discussed in the following section.

\section{The Nature of the Photo-Induced States of Transition Metal Nitrosyl Compounds}

Our structure determinations of a number of transition metal nitrosyl complexes prior and following low-temperature irradiation show that the photo-induced states are not electronically excited states, but rather linkage isomers in 


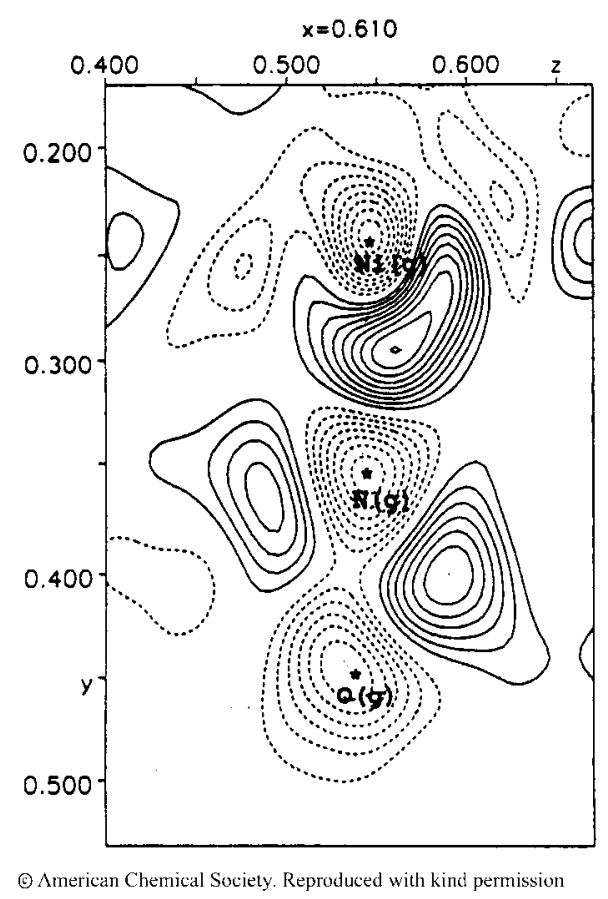

Figure 3. Difference in electron density between the photoirradiated $\left[\mathrm{Ni}(\mathrm{NO})\left(\eta^{5}-\mathrm{Cp}\right)\right]$ crystal and ground state molecules. Contours at $0.4 e \AA^{-3}$. Negative contours dotted. ${ }^{19}$

which the nitrosyl ligand is bound through the oxygen atom (MS1), or sideways $\left(\eta^{2}\right)$ through both oxygen and nitrogen (Scheme 1). ${ }^{12}$ For MS2 the evidence is based directly on the photodifference maps, which show an electron-deficient valley in the region of the terminally bound NO group, and photo-induced density in the plane perpendicular to the ground state NO ligand (Fig. 3). For the isonitrosyl group in MS1 the evidence is somewhat more circumstantial, but quite abundant. It became first clear for sodium nitroprusside (SNP), when a charge density refinement of the light-induced state indicated a larger valence electron

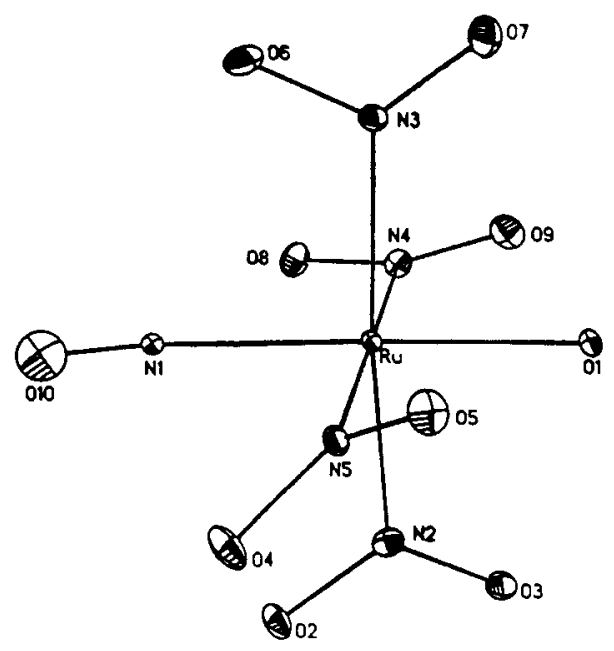

(a) American Chemical Society. Reproduced with kind permission population on the proximal atom than on the distal atom of the NO group. ${ }^{13}$ It is well known that incorrect element assignment leads to dramatic anomalies in atomic displacement parameters from crystallographic analyses. ${ }^{14}$ Least squares refinements of the light-induced state resulted in very large anomalies for the atomic displacement parameters when the N-bounded geometry was selected, with the terminal atom having mean-square displacements up to 20 times larger than those of the proximal atom. Introduction of the isonitrosyl geometry leads to a physically meaningful result, as shown in Fig. 4 for $\mathrm{K}_{2}\left[\mathrm{RuNO}\left(\mathrm{NO}_{2}\right)_{4} \mathrm{OH}\right] .{ }^{15}$

Güdel pointed out earlier ${ }^{16}$ that the longevity of the induced species is inconsistent with any one-electron transfer model; and that either a large structural change, or a multi-electron promotion is required to explain the stability. The finding that the metastable states are linkage isomers rather than electronically excited states provides a logical explanation for this apparent paradox, and is in agreement with the observed diamagnetism of the new species. ${ }^{17,18}$

DFT calculations confirm that the new linkage isomers correspond to local minima on the potential energy surface of the diamagnetic ground state. Theoretical geometry optimization leads to quite reasonable agreement with experimental geometries. ${ }^{19}$ Though both states have not been observed for all photoactive complexes, this should not be interpreted as indicating the absence of the second isomer. For the $\{\mathrm{M}(\mathrm{NO})\}^{10}\left[\mathrm{Ni}(\mathrm{NO})\left(\eta^{5}-\mathrm{Cp}\right)\right]$ complex, for example, for which the photo-induced state was first observed by IR in $1977,{ }^{6}$ only the MS2 state was reported until very recently Guida et al. discovered the existence of MS1 by IR of a concentrated liquid sample. ${ }^{20}$

The full mechanism of the isomerization process remains to be unraveled, but it is clear that a HOMO-LUMO transition to an excited state occurs upon irradiation, and that the excited state subsequently relaxes into a subsidiary minimum on the ground state surface. This is well illustrated by the DFT calculation of SNP by Delley et al., ${ }^{21}$ the results

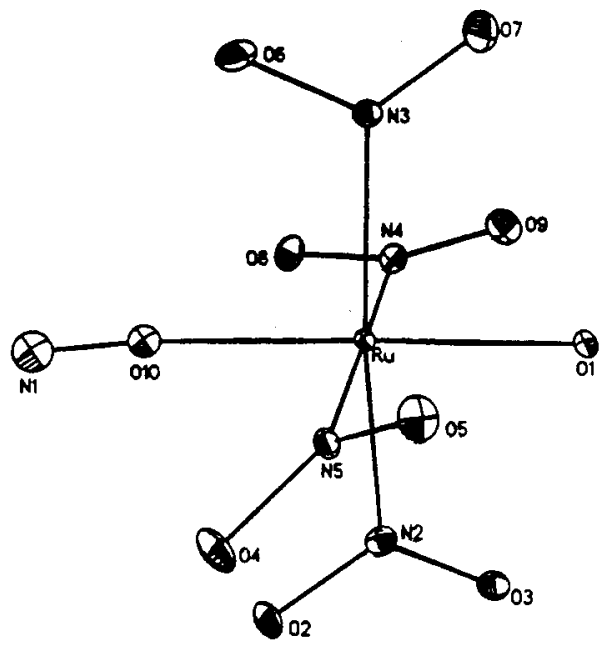

Figure 4. ORTEP drawings of the Ru-NO (left) and Ru-ON (right) models for the MS1 excited state of the $\left[\mathrm{Ru}(\mathrm{OH})(\mathrm{NO})(\mathrm{NO})_{4}\right]^{2-}$ anion, showing the differences in the nitrosyl thermal parameters. Thermal parameters for the other atoms are the same as those for the ground-state molecules. 50\% probability ellipsoids are shown. The hydroxyl-hydrogen atom has been omitted. ${ }^{15}$ 


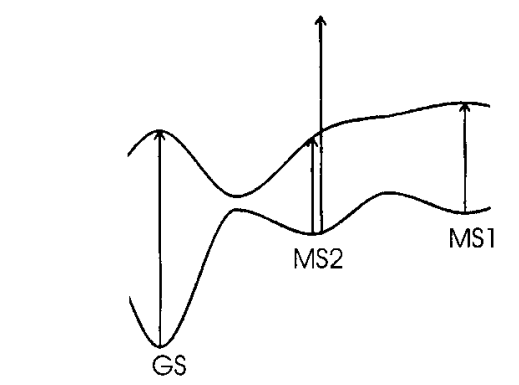

(c) American Institute of Physics. Reproduced with kind permission

Figure 5. Theoretical reaction coordinate according to Delley et al. ${ }^{21}$

of which are shown in Fig. 5. In agreement with thermochemical data, the side-bound MS2 state is found to be slightly lower in energy than the MS1 state, which lies $\sim 1.1 \mathrm{eV}$ above the ground state according to the experimental data. Our calculations on $\mathrm{Ru}$-nitrosyls (see below) give larger energy differences between MS1 and the ground state of $1.6 \mathrm{eV}$ or more. The spectroscopic and thermal transitions that can be induced are schematically illustrated in Fig. 6.

\section{Chemical Substitution and the Stability of the NO Linkage Isomers}

The metastable NO linkage isomers that were known up to 1995 invariably decayed back to the ground state at temperatures at or below about $200 \mathrm{~K}$, as illustrated for SNP in Fig. 1. As the NO transition metal complexes have

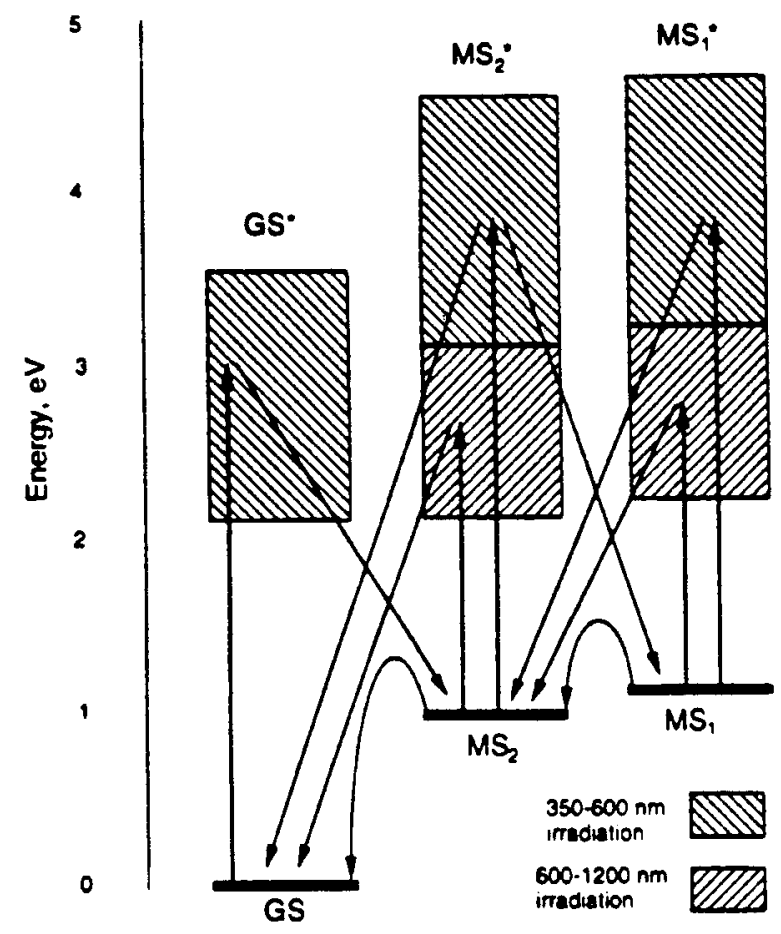

C) American Chemical Society. Reproduced with kind permission

Figure 6. Proposed relationship and interconversion pathways between the different states of SNP. Straight vertical arrows are electronic transition. Slanted arrows combine an electronic transition with nuclear motion. Curved arrows are radiationless thermal decay processes. ${ }^{12}$ potential as write-read storage devices, raising the decay temperature is of practical importance. The light-induced molecular change is accompanied by a significant variation of the color and the refractive index of the crystals. This means that patterns can be written into the crystals by a light beam. Moreover, the change can be reversed by irradiation with longer wavelength light. ${ }^{22}$ The feasibility of very highdensity memory devices based on these properties has been demonstrated. ${ }^{23-25}$ The question then arises: can complexes stable at higher temperatures be synthesized, and what are the factors influencing stability?

To explore the factors influencing stability of the NO linkage isomers, we have prepared a series of ruthenium nitrosyl derivatives. We find chemical substitution to be an effective means of varying the properties of the complexes. This is illustrated in Fig. 7, which shows the difference DSC curves (defined as difference between the dark and the photoexposed sample traces) for the $\mathrm{NO}_{3}$ and $\mathrm{PF}_{6}$ salts of $\left[\mathrm{Ru}(\mathrm{NO})\left(\mathrm{NH}_{3}\right)_{5}\right]^{3+}$. For these compounds the MS1 peaks occur at 260 and $267 \mathrm{~K}$, respectively, thus much higher decay temperatures are achievable by chemical substitution.

Subsequent studies showed the decay temperature for complexes with different trans ligands to correlate, with one notable exception, with the stretching frequency of the $\mathrm{N}-\mathrm{O}$ bond (Fig. 8). The trans influence on the strength of the bond trans to the substituted ligand is well known, ${ }^{26}$ and related to the strength of the $\pi$-acceptor properties of the ligand. In the $\mathrm{Ru}$ complexes back-donation from the metal to the nitrosyl group occurs through $\pi$-bonding between the Ru d-orbitals and the NO $\pi^{*}$-antibonding orbitals. Thus metal-NO $\pi$-bonding weakens the $\mathrm{N}-\mathrm{O}$ bond and decreases the $\mathrm{N}-\mathrm{O}$ stretching frequency. We find that the stronger the $\pi$-withdrawing properties of the trans ligand, and thus the weaker the $\pi$-bonding to $\mathrm{NO}$ in the ground state, the larger the stability of the linkage isomers. Though the series of compounds investigated is incomplete, the observed trend indicates that electronic effects play a dominant role in the relative stability of the NO linkage isomers.

DFT calculation shed further light on the correlation. To compare the effect of the trans ligand we have performed a series of calculations on the relative height of the energy minima corresponding to the MS1, MS2 and ground state isomers of $\mathrm{K}_{2}\left[\mathrm{Ru}(\mathrm{NO}) \mathrm{LCl}_{4}\right]$, varying the trans ligand $\mathrm{L}$ without changing the equatorial ligands. All calculations were performed using the Amsterdam Density Functional program, version 1999.02. ${ }^{\dagger 27}$ The results are summarized in Table 1. In all cases the linkage isomers correspond to stable species on the ground state energy surface.

\footnotetext{
For C, N, O and halogen atoms the valence shells were described using a triple-s STO basis set, augmented by one d-STO polarization function (ADF database IV). The atomic orbitals of hydrogen were described by double- $s$ basis set, augmented by one p-STO polarization function. For the $\mathrm{ns}, \mathrm{np}, \mathrm{nd},(n+1) \mathrm{s}$ and $(n+1) \mathrm{p}$ shells on Ru, a triple-s STO basis set was employed, augmented by exponential decay factor. The $1 \mathrm{~s}^{2}$ shell of $\mathrm{C}, \mathrm{N}, \mathrm{O}$, $1 s^{2} 2 s^{2} 2 p^{6}$ of halogens and the $1 s^{2} 2 s^{2} 2 p^{6} 3 s^{2} 3 p^{6} 3 d^{10}$ shells of Ru were treated by frozen-core approximation. All calculations were based on the local density approximation (LDA) in the parametrization of Vosko, Wilk and Nusair (VWN) (Vosko, S. H.; Wilk, L.; Nusair, M. Can. J. Phys. 1980, 58, 1200-1211)
} 


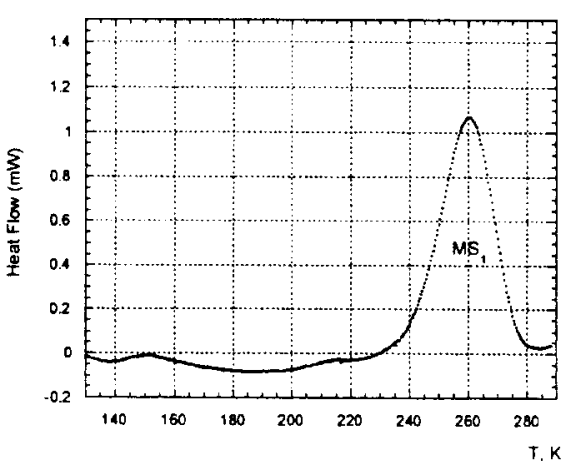

(a)

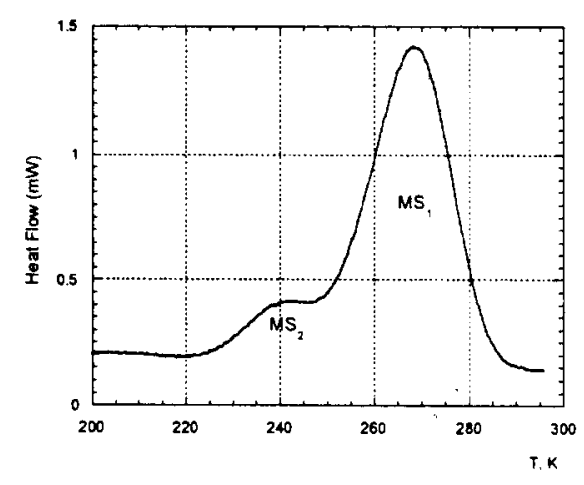

(b)

Figure 7. Difference DSC curves for: (a) $\left[\mathrm{Ru}\left(\mathrm{NH}_{3}\right)_{5}(\mathrm{NO})\right]\left(\mathrm{NO}_{3}\right)_{3}$, and (b) $\left[\mathrm{Ru}\left(\mathrm{NH}_{3}\right)_{5}(\mathrm{NO})\right]\left(\mathrm{PF}_{6}\right)_{3}$.

Examination of the results shows the energy differences between the ground and MS1 states to be generally larger for the more stable MS1 linkage isomers listed towards the right of the table. In other words, the linkage isomers with the higher decay temperatures are the ones with a higher energy relative to the ground state. This implies that the decreased $\pi$-back bonding weakens the $\mathrm{Ru}$-isonitrosyl interaction more than the $\mathrm{Ru}$-nitrosyl bonding. The implication then is that the bonding in the rate-determining transition state is even more weakened, leading to a higher energy barrier for return to the ground state. The decrease in metal-NO $\pi$-bonding evidently affects not only the energy of the MS1 linkage isomers but also the barrier to transition back to the ground state. The energy differences for the bidentate MS2, listed in the third row of Table 1, show much less variation, indicating the different nature of the metal-NO bonding in the MS2 geometry.

\section{Solid State Effects}

Is there any effect of the space restrictions that must exist in the solid state on the possibility for reorientation of the nitrosyl ligand?

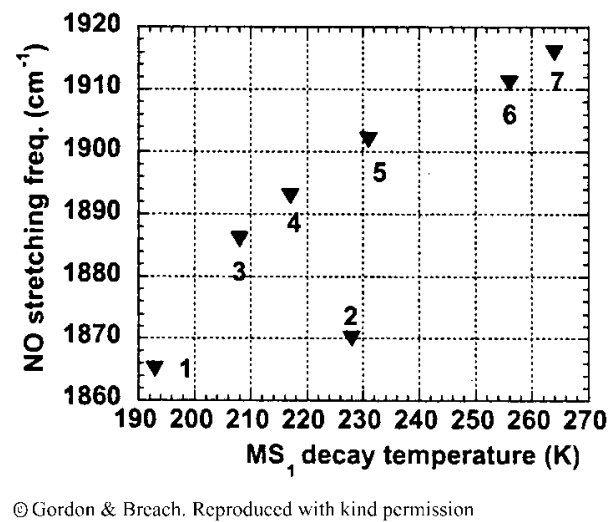

Figure 8. Decay temperature of MS1 as a function of the ground-state NO stretching frequency. 1: $\left[\mathrm{Ru}(\mathrm{NO})(\mathrm{bpy})\left(\mathrm{NO}_{2}\right)(\mathrm{OH})\left(\mathrm{H}_{2} \mathrm{O}\right)\right]\left[\mathrm{NO}_{2}\right], 2$ : $\left[\mathrm{Ru}(\mathrm{NO})(\mathrm{OH})(\mathrm{py})_{4}\right]\left[\mathrm{PF}_{6}\right]_{2}, 3: \mathrm{K}_{2}\left[\mathrm{Ru}(\mathrm{NO})\left(\mathrm{NO}_{2}\right)_{4}(\mathrm{OH})\right] ; 4: \mathrm{K}_{2}\left[\mathrm{Ru}(\mathrm{NO}) \mathrm{Cl}_{5}\right]$; 5: $\left[\mathrm{Ru}(\mathrm{NO}) \mathrm{Br}(\mathrm{py})_{4}\right]\left[\mathrm{PF}_{6}\right]_{2} ; 6:\left[\mathrm{Ru}(\mathrm{NO}) \mathrm{Cl}(\mathrm{py})_{4}\right]\left[\mathrm{PF}_{6}\right]_{2} ; 7:\left[\mathrm{Ru}(\mathrm{NO})\left(\mathrm{NH}_{3}\right)_{5}\right]-$ $\left[\mathrm{NO}_{3}\right]_{3} \cdot{ }^{39}$
Ohashi et al. ${ }^{28}$ have defined the reaction cavity as the space limited by the van der Waals radii of the adjacent nonbonded atoms plus a radial increment of $1.2 \AA$. For intermolecular distances, the radius of the atom(s) bonded to the ligand is (are) taken to be the bond length, so that the nucleus of the bonded atom of the reactive ligand is located at the boundary of the cavity. This definition, which is not unique, has been useful in providing insight into the solidstate racemization of $-\mathrm{C}^{*} \mathrm{H}\left(\mathrm{CH}_{3}\right) \mathrm{CN}$ (cyanoethyl) substituted cobalt complexes. Volumes of the reaction cavities for a number of nitrosyl complexes, calculated in this manner, are listed in Table 2 together with the corresponding MS1 decay temperatures. The volume of the reaction

Table 1. Calculated energy differences $(\mathrm{eV})$ with ground state for $\mathrm{K}_{2}\left[\mathrm{Ru}(\mathrm{NO}) \mathrm{LCl}_{4}\right]$ MS1 and MS2 linkage isomers and corresponding decay temperatures. Compounds are listed in order of increasing NO stretching frequency

\begin{tabular}{lcccccl}
\hline $\mathrm{L}=$ & $\mathrm{NO}_{2}^{-}$ & $\mathrm{OH}^{-}$ & $\mathrm{Cl}^{-}$ & $\mathrm{NH}_{3}$ & $\mathrm{H}_{2} \mathrm{O}$ & Nicotinamide \\
\hline MS1 & 1.643 & 1.730 & 1.765 & 1.871 & 2.007 & 1.812 \\
MS2 & 1.107 & 1.393 & 1.510 & 1.371 & 1.488 & 1.377 \\
$T_{\mathrm{d}}^{\mathrm{a}}$ & & $208^{\mathrm{b}}$ & $216^{\mathrm{c}}$ & $260^{\mathrm{d}}$ & & \\
\hline
\end{tabular}

${ }^{\mathrm{a}} T_{\mathrm{d}}$ : decay temperature for MS1.

${ }^{\mathrm{b}}$ For $\mathrm{K}_{2}\left[\mathrm{Ru}(\mathrm{NO})\left(\mathrm{NO}_{2}\right)_{4}(\mathrm{OH})\right]$.

${ }^{\mathrm{c}}$ For $\mathrm{K}_{2}\left[\mathrm{Ru}(\mathrm{NO}) \mathrm{Cl}_{5}\right]$.

${ }^{\mathrm{d}}$ For $\left[\mathrm{Ru}\left(\mathrm{NH}_{3}\right)_{5}(\mathrm{NO})\right]\left[\mathrm{NO}_{3}\right]_{3}$.

Table 2. Volume of the reaction cavity for a number of nitrosyl complexes

\begin{tabular}{llc}
\hline COMPOUND & ${\text { Volume } \AA^{3}}$ & $T_{\mathrm{d}}(\mathrm{MS} 1)(\mathrm{K})$ \\
\hline $\mathrm{Ni}(\mathrm{NO})\left(\eta^{5}-\mathrm{Cp}^{\mathrm{A}}\right)$ & 3.436 & \\
Molecule A & 3.058 & $\sim 50$ (MS2) \\
Molecule B & 1.101 & 195 \\
$\mathrm{Na}_{2}\left[\mathrm{Fe}(\mathrm{CN})_{5} \mathrm{NO}\right]_{2} \mathrm{H}_{2} \mathrm{O}$ & 1.507 & 180 \\
$\mathrm{Na}_{2}(18-\mathrm{crown}-6)_{2}$ & & \\
{$\left[\mathrm{Fe}(\mathrm{CN})_{5} \mathrm{NO}\right] \cdot 8 \mathrm{H}_{2} \mathrm{O}^{38}$} & & \\
$\left.\left[\mathrm{Ru}(\mathrm{NH})_{3}\right)_{5}(\mathrm{NO})\right]\left(\mathrm{NO}_{3}\right)_{3}{ }^{\mathrm{a}}$ & 0.340 & 260 \\
$\mathrm{Ru} 1-\mathrm{N}-\mathrm{O}$ & 0.403 & \\
$\mathrm{Ru} 2-\mathrm{N}-\mathrm{O}$ & 0.835 & 260 \\
$\mathrm{Ru} 3-\mathrm{N}-\mathrm{O}$ & 0.913 & \\
$\mathrm{Ru}(\mathrm{NH})_{5}(\mathrm{NO}) \mathrm{Cl}_{3} \mathrm{H}_{2} \mathrm{O}$ &
\end{tabular}

${ }^{\mathrm{a}} \mathrm{A}$ fourth independent molecule in the asymmetric unit is disordered. 


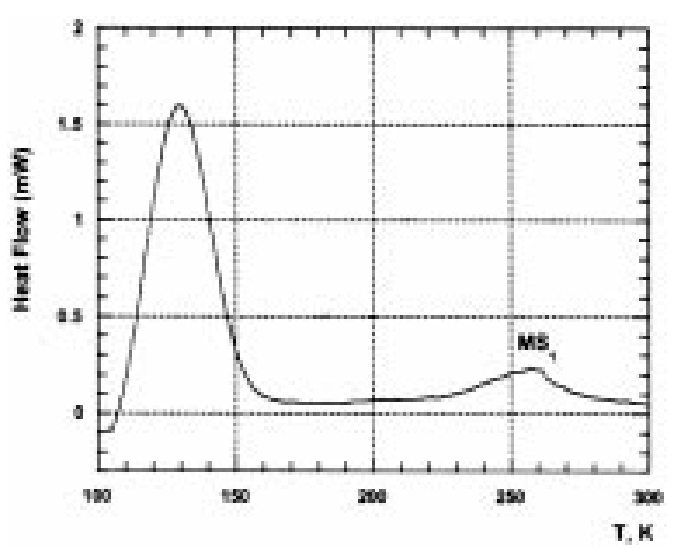

Figure 9. Difference DSC curve of $\left[\mathrm{Ru}\left(\mathrm{NH}_{3}\right)_{5}(\mathrm{NO})\right]\left[\mathrm{NO}_{3}\right]_{3}$ in a microporous silica gel glass. The curve for the neat crystal is shown in Fig. 7a.

cavity in the different solids varies over a wide range, and is very small for $\left[\mathrm{Ru}\left(\mathrm{NH}_{3}\right)_{5}(\mathrm{NO})\right]\left(\mathrm{NO}_{3}\right)_{3}$ in which the oxygen of the NO group makes short intermolecular $\mathrm{O}-\mathrm{O}$ contacts with other oxygen atoms. It should be noted that as the cavity is defined by adding $1.2 \AA$ to the radii of the atoms lining the cavity, even small cavity sizes allow some atomic motion.

It is evident from Table 2 that there is no clear correlation between the size of the reaction cavity and the MS1 decay temperature. The most informative comparison is between $\mathrm{Na}_{2}\left[\mathrm{Fe}(\mathrm{CN})_{5} \mathrm{NO}\right] \cdot 2 \mathrm{H}_{2} \mathrm{O}(\mathrm{SNP})$ and the co-crystal of SNP with 18-crown-6 ether of composition $\mathrm{Na}_{2}$ (18-crown$6)_{2}\left[\mathrm{Fe}(\mathrm{CN})_{5} \mathrm{NO}\right] \cdot 8 \mathrm{H}_{2} \mathrm{O}$. The reaction cavity is substantially larger for the latter, 1.507 vs. $1.101 \AA^{3}$, but the decay temperature is lower by $15^{\circ}$. It is plausible that the larger cavity allows easier thermal return to the ground state, but more data are required before a definite conclusion can be drawn, as induced polarization, which varies with the crystal matrix, ${ }^{29}$ may also be a factor.

That the crystal cavity can affect the orientation of the sidebound nitrosyl ligand is evident from the results on $\left[\mathrm{Ni}(\mathrm{NO})\left(\eta^{5}-\mathrm{Cp}^{*}\right)\right]$. The complex crystallizes in a monoclinic $P 2{ }_{1} / c$ cell with two independent molecules in the asymmetric unit. For one of the two molecules the sidebound nitrosyl ligand is fully ordered, but two different orientations occur for the second molecule. Examination

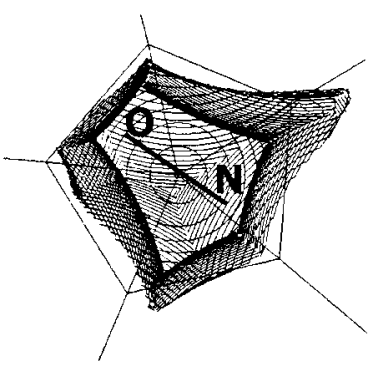

(a) of the reaction cavity suggests the orientation to be strongly influenced by the shape of the cavity (Fig. 10).

The effect of the solid state environment is also evident in DSC data obtained on a sample of $\left[\mathrm{Ru}(\mathrm{NO})\left(\mathrm{NH}_{3}\right)_{5}\right]\left(\mathrm{NO}_{3}\right)_{3}$ absorbed in microporous silica gel glass. While the decay temperature of MS1 is the same in the neat crystal and the glass, there is a dramatic difference in the relative populations in the two media, the peak being strong in the neat crystal and quite weak in the glass. Comparison of the DSC curves for the $\mathrm{NO}_{3}$ and $\mathrm{PF}_{6}$ salts (Fig. 7) suggests that the MS2 peaks in the neat crystals occur at 220-240 K, though the peak is very weak for the nitrate salt. For the complex absorbed in the glass (Fig. 9), a pronounced peak occurs at about $130 \mathrm{~K}$. This peak, which is just discernable in the neat nitrate crystals, could correspond to MS2, but perhaps more likely to a hitherto unidentified species. One might conjecture that MS2, or the different linkage isomer, is favored because more space is available in the nanophase in the glass. Further experiments are clearly needed to elucidate this observation.

\section{Other Diatomic Ligands: $\eta^{2}$ Side-Bound Dinitrogen}

While side-bound $\mathrm{O}_{2}$ complexes like $\mathrm{Ti}\left(\mathrm{H}_{2} \mathrm{O}\right)_{2}($ dipic $)\left(\mathrm{O}_{2}\right)$ and $\operatorname{IrCl}(\mathrm{CO})\left(\mathrm{O}_{2}\right)\left(\mathrm{PPh}_{3}\right)_{2}{ }^{30}$ have been known for quite some time, the side-bound $\eta^{2}$-NO ligand has not been observed previously. Can similar metastable isomers be generated for other diatomic molecules such as $\mathrm{N}_{2}$ and $\mathrm{CO}$ ? There are indirect indications in the literature that the answer is positive, at least for $\mathrm{N}_{2}$. In 1970 , for example, Armor and Taube interpreted IR spectra of isotopically labeled $\left[\mathrm{Ru}\left(\mathrm{NH}_{3}\right)_{5}\left({ }^{15} \mathrm{NN}\right)\right]^{2+}$ in terms of end-to-end rotation of $\mathrm{N}_{2}$ taking place through the side-on bound state of $\mathrm{N}_{2}{ }^{31}$ We selected the osmium analogue, $\left[\mathrm{Os}\left(\mathrm{NH}_{3}\right)_{5}\left(\mathrm{~N}_{2}\right)\right]\left[\mathrm{PF}_{6}\right]_{2}$, for the study, as maximal overlap between d-orbitals of the metal and $2 p$ orbitals of the $\eta^{2}$-bound $\mathrm{N}_{2}$, and thus maximal stability, can be expected for third row transition metals. The formation of a new species upon irradiation of the Os salt was observed by both DSC and IR spectroscopy. ${ }^{32}$ The DSC shows a peak centered at about $218 \mathrm{~K}$, corresponding to the thermal decay of the light-induced species. Assuming an energy difference between the metastable and ground states of $1 \mathrm{eV}$, as for $\eta^{2}-\mathrm{NO}$ in sodium nitroprusside, ${ }^{33}$ the peak corresponds to a metastable state population of $19 \%$. The IR spectrum taken at $100 \mathrm{~K}$ shows a

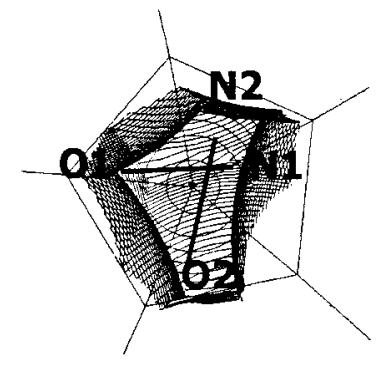

(b)

Figure 10. Reaction cavities for the two crystallographically independent molecules of $\left[\mathrm{Ni}(\mathrm{NO})\left(\eta^{5}-\mathrm{Cp}\right)\right]$, and the orientation of the NO ligand in the sidebound MS2 isomer, as determined experimentally: (a) Molecule A, (b) Molecule B. 

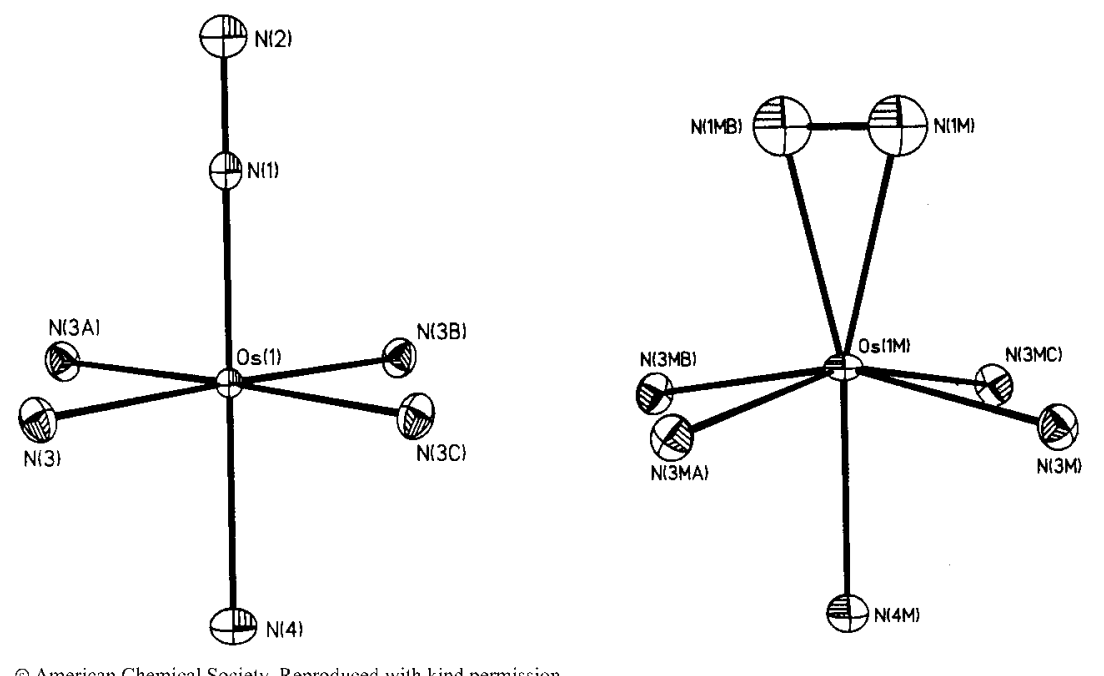

Figure 11. ORTEP diagrams of the $\left[\mathrm{Os}\left(\mathrm{NH}_{3}\right)_{5}\left(\mathrm{~N}_{2}\right)\right]^{2+}$ ion in $\left[\mathrm{Os}\left(\mathrm{NH}_{3}\right)_{5}\left(\mathrm{~N}_{2}\right)\right]\left[\mathrm{PF}_{6}\right]_{2}$. Ellipsoids are $50 \%$ probability surfaces. Left: Ground State; Right: Lightinduced Metastable State. Hydrogen atoms omitted for clarity. The bending of the equatorial ligands away from the side-bound dinitrogen is evident. ${ }^{32}$

light-induced band of the $\left[\mathrm{Os}\left(\mathrm{NH}_{3}\right)_{5}\left(\mathrm{~N}_{2}\right)\right]\left[\mathrm{PF}_{6}\right]_{2}$ species at $1838 \mathrm{~cm}^{-1}$, downshifted by $187 \mathrm{~cm}^{-1}$ from the $2025 \mathrm{~cm}^{-1}$ band assigned to the stretching vibration of $\left(\eta^{1}\right) \mathrm{N}_{2}$. As for the nitrosyl complexes, the process is thermally reversed when the light is switched off and the sample warmed to room temperature.

The results of the photo-crystallographic experiment, shown in Fig. 11, confirm the existence of an $\eta^{2}$ metastable state, with a population of $17.4(5) \%$, quite comparable to the population reached in the DSC experiment described above. As may be expected, changes in the bond lengths upon transition from the $\eta^{1}-\mathrm{N}_{2}$ to the $\eta^{2}-\mathrm{N}_{2}$ configuration are quite large: the axial Os- $\mathrm{N}\left(\mathrm{NH}_{3}\right)$ bond shortens by $0.054(14) \AA$, while the equatorial $\mathrm{Os}-\mathrm{N}\left(\mathrm{NH}_{3}\right)$ bonds are elongated by $0.034(7) \AA$. The most pronounced change occurs for the Os-N $\left(\mathrm{N}_{2}\right)$ bond, which lengthens by $0.263(17) \AA$.

Like for the NO complexes, Density Functional calculations, performed with the ADF package, confirm that the experimentally observed geometry of $\left[\mathrm{Os}\left(\mathrm{NH}_{3}\right)_{5}\left(\eta^{2}-\mathrm{N}_{2}\right)\right]^{2+}$ corresponds to a local minimum on the potential energy surface, and gives geometry changes which are generally in agreement with those found experimentally. The minimum is located $\sim 0.82 \mathrm{eV}$ above the ground state energy, a value somewhat smaller than that found for the side-bound NO complexes.

\section{Concluding Remarks}

In addition to the fundamental importance of the reactions described above, the mode of bonding of small molecules to transition metal atoms is of biological relevance. Nitric oxide plays a crucial role in several biologically processes such as intercellular signal transduction, blood pressure regulation, and cytotoxic activity of immune systems. ${ }^{34}$ We have found that metastable $\eta^{1}$-NO and $\eta^{2}$-NO linkage isomers are also formed on low-temperature irradiation of the nitrosyl metalloporphyrins $(\mathrm{OEP}) \mathrm{Ru}(\mathrm{NO}) \mathrm{L}(\mathrm{L}=\mathrm{O}-\mathrm{i}$ $\left.\mathrm{C}_{5} \mathrm{H}_{11}, \mathrm{SCH}_{2} \mathrm{CF}_{3}\right),{ }^{35}$ and may thus play a role in NO binding to the heme group. Similarly, the coordination geometry of $\mathrm{N}_{2}$ has attracted renewed attention with the elucidation of the atomic resolution $(2.7 \AA)$ structure of the MoFe-protein of the catalytic enzyme nitrogenase ${ }^{36}$ for which the binding mode of $\mathrm{N}_{2}$ is as yet unknown.

The stability of the NO linkage isomers is clearly dominated by electronic factors, though solid state effects cannot be completely ignored, as is clear of the variation of the metastable state decay temperatures between different salt of the same ion, between sodium nitroprusside in the neat crystal and in its complex with 18-crown-6, and by the effect of particle size on the MS1/MS2 ratio for $\left[\mathrm{Ru}\left(\mathrm{NH}_{3}\right)_{5}\right.$ $(\mathrm{NO})]\left(\mathrm{NO}_{3}\right)_{3}$.

Finally, we note that the photocrystallographic technique applied in the work described above is not limited to the study of metastable species, but can be used with some modifications to determine the structure of short-lived transient species in solids. ${ }^{37}$

\section{Acknowledgements}

We would like to thank Prof P. N. Prasad and Dr A. M. Biswas for the preparation of the sol-gel glass sample containing $\left[\mathrm{Ru}\left(\mathrm{NH}_{3}\right)_{5}(\mathrm{NO})\right]\left(\mathrm{NO}_{3}\right)_{3}$, and Prof Kim Bagley of Buffalo State College for access to the IR equipment used to obtain the results shown in Fig. 2. Support of this work by the National Science Foundation (CHE9615586 and CHE9981864) and the Petroleum Research Fund administered by the American Chemical Society (PRF32538AC3) is gratefully acknowledged. The Center for Computational Research at SUNY/ Buffalo at which calculations were performed is supported by grant (DBI9871132) from the National Science Foundation. 


\section{References}

1. (a) Hauser, U.; Oestreich, V.; Rohrweck, H. D. Z. Physik A 1977, 280, 17-25. (b) Hauser, U.; Oestreich, V.; Rohrweck, H. D. Z. Physik A 1977, 280, 125-130.

2. (a) Woike, Th.; Krasser, W.; Bechthold, P. S.; Haussühl, S. Solid State Commun. 1983, 45, 499-502. (b) Woike, Th.; Krasser, W.; Bechthold, P. S.; Haussühl, S. Phys. Rev. Lett. 1984, 53, 17671770 .

3. Zollner, H.; Woike, Th.; Krasser, W. Z. Kristallogr. 1989, 188, 139-153.

4. Rüdlinger, M.; Schefer, J.; Vogt, T.; Woike, Th.; Haussühl, S.; Zöllner, H. Z. Phys. B 1992, 180/181, 293-298.

5. Woike, Th.; Zöllner, H.; Krasser, W.; Haussühl, S. Solid State Commun. 1990, 73, 149-152.

6. Crichton, O.; Rest, A. J. J. Chem. Soc., Dalton Trans. 1977, 986-993.

7. Enemark, J. H.; Feltham, R. D. Coord. Chem. Rev. 1974, 13, 339-406.

8. White, M. A.; Pressprich, M. R.; Coppens, P.; Coppens, D. D. J. Appl. Crystallogr. 1994, 27, 727-732.

9. Güida, J. A.; Aymonino, P. J.; Piro, O. E.; Castellano, E. E. Spectrochim. Acta A 1993, 49, 535-542.

10. Güida, J. A.; Piro, O. E.; Schaiquevich, P. S.; Aymonino, P. J. Solid State Commun. 1997, 101, 471-475.

11. Güida, J. A.; Piro, O. E.; Aymonino, P. J. Inorg. Chem. 1995, 34, 4113-4116.

12. Carducci, M. D.; Pressprich, M. R.; Coppens, P. J. Am. Chem. Soc. 1997, 119, 2669-2678.

13. Pressprich, M. R.; White, M. A.; Vekhter, Y.; Coppens, P. J. Am. Chem. Soc. 1994, 116, 5233-5238.

14. Harlow, R. L. J. Res. NIST 1996, 101, 327-339.

15. Fomitchev, D. V.; Coppens, P. Inorg. Chem. 1996, 35, 70217026 .

16. Güdel, H. U. Chem. Phys. Lett. 1990, 175, 262-266.

17. Woike, Th.; Kirchner, W.; Kim, H.; Haussühl, S.; Rusanov, V.; Angelov, V.; Ormandjiev, S.; Bonchev, Ts.; Schroeder, A. N. F. Woike. Hyperfine Interact. 1993, 7, 265-275.

18. Terrile, C.; Nascimento, O. R.; Moraes, I. J.; Castellano, E. E.; Piro, O. E.; Güida, J. A.; Aymonino, P. J. Solid State Commun. 1990, 73, 481-486.

19. Fomitchev, D. V.; Furlani, T. R.; Coppens, P. Inorg. Chem. 1998, 37, 1519-1526.

20. Schaiquevich, P. S.; Güida, J. A.; Aymonino, P. J. Inorg. Chim. Acta 2000, 303, 277-281.

21. Delley, B.; Schefer, J.; Woike, Th. J. Chem. Phys. 1997, 107, 10067-10074.
22. Woike, Th.; Kirchner, W.; Schetter, G.; Barthel, Th.; Hyungsang, K.; Haussühl, S. Opt. Commun. 1994, 106, 6-10.

23. Woike, Th.; Haussühl, B.; Rupp, R. A.; Beckers, J.; Imlau, M.; Schieder, R. Physics B 1996, 243-248.

24. Woike, Th.; Imalau, M.; Haussühl, S.; Rupp, R. A.; Schieder, R. Phys. Rev. B 1998, 58, 8411-8415.

25. Imalau, M.; Woike, Th.; Schieder, R.; Rupp, R. A. Phys. Rev. Lett. 1999, 82, 2860-2863.

26. Cotton, F. A.; Wilkinson, G. Advanced Inorganic Chemistry; 5th ed.; Wiley-Interscience: New York, 1988 (pp 1299).

27. The Amsterdam Density Functional program package, v.1999.02; The Theoretical Chemistry group of the Vrije Universiteit in Amsterdam and the Theoretical Chemistry group of the University of Calgary, Canada with significant contributions from academic collaborators elsewhere. Baerends, E. J.; Ellis, D. E.; Ros, P. Chem. Phys. 1973, 2, 41-51; te Velde, G.; Baerends, E. J. J. Comp. Phys. 1992, 99, 84-98. Fonseca Guerra, C.; Visser, O.; Snijders, J. G., te Velde, G.; Baerends, E. J. In Methods and Techniques for Computational Chemistry (METECC-5); Clementi, E., Corongiu, G., Eds.; STEF: Cagliari, 1995; pp 303-395.

28. Ohashi, Y.; Yanagi, K.; Kurihara, T.; Sasada, Y.; Ohgo, Y. J. Am. Chem. Soc. 1981, 103, 5805-5812; http://eels.kuicr.kyotou.ac.jp/ tnemoto/crystal/cavity/index.html.

29. Zhang, Y.; Coppens, P. Chem. Comm. 1999, 23, 2425-2426.

30. Schwarzenbach, D. Helv. Chim. Acta 1972, 55, 2990-3004;

Laing, M.; Nolte, M. J.; Singelton, E. J. Chem. Soc., Chem. Commun. 1975, 660-661.

31. Armor, J. N.; Taube, H. J. Am. Chem. Soc. 1970, 92, 25602562.

32. Fomitchev, D. V.; Bagley, K. A.; Coppens, P. J. Am. Chem. Soc. 2000, 122, 532-533.

33. Hauser, U.; Oestrich, V.; Rohrweck, R. D. Z. Phys. A 1978, 284, 9-19.

34. Nitric Oxide, Methods in Enzymology; Packer, L., Ed.; Academic: San Diego, 1996; Vols. 268/269 (see also 1999; Vol. 301).

35. Fomitchev, D. V.; Coppens, P.; Li, T.; Bagley, K. A.; Chen, L.; Richter-Addo, G. B. Chem. Commun. 1999, 2013-2014.

36. Georgiadis, M. M.; Komiya, H.; Chakrabarti, P.; Woo, D.; Kornuc, J. J.; Rees, D. C. Science 1992, 257, 1653-1659; Kim, J.; Rees, D. C. Science 1992, 257, 1677-1682.

37. Coppens, P. Synchr. Rad. News 1997, 10, 26-30; Fullagar, W. K.; Wu, G.; Kim, C.; Ribaud, L.; Sagerman, G.; Coppens, P. J. Synchr. Rad. in press.

38. Zhang, Y.; Kim, C. D.; Coppens, P. to be published.

39. Fomitchev, D. V.; Coppens, P. Comments Inorg. Chem. 1999, 21, 131-148. 